\title{
A Microeconomics Explanation of the Environmental Kuznets Curve (EKC) and an Empirical Investigation
}

\author{
Shuo Wang1*, Fenglin Yang², Xian'En Wang ${ }^{1}$, Junnian Song ${ }^{1}$ \\ ${ }^{1}$ College of Environment and Resources, Jilin University, \\ Changchun 130012, China \\ ${ }^{2}$ Key Laboratory of Industrial Ecology and Environmental Engineering (China Ministry of Education), \\ School of Environmental Science and Technology, Dalian University of Technology, \\ Linggong Road 2, Dalian, 116024, P.R. China
}

Received:25 November 2016

Accepted: 18 January 2017

\begin{abstract}
This paper attempts to give a microeconomic explanation of the environmental Kuznets curve (EKC) hypothesis according to marginal cost and marginal revenue. The interpretation about the shape and inflection point of EKC is based on the comparison between marginal cost and marginal revenue. The emissions of carbon dioxide $\left(\mathrm{CO}_{2}\right)$, nitrous oxide $\left(\mathrm{N}_{2} \mathrm{O}\right)$ and methane are used as the environmental indicators and GDP per person is used as the economic indicator. Through the analysis of U.S. data from 1960 to 2010, we investigated the EKC hypothesis using the co-integration and correlation methods. The curve of $\mathrm{CO}_{2}$ versus GDP per person in the U.S. is a wave shape in a different time scale. The relationship between $\mathrm{N}_{2} \mathrm{O}$ and GDP per person showed the same trend with $\mathrm{CO}_{2}$. The EKC curve between the methane and the GDP per person from 1990 to 2009 is a U-shape. Thus, we analyzed the relationship according to the microeconomic explanation of the EKC.
\end{abstract}

Keywords: environmental Kuznets curve, marginal cost, marginal revenue, $\mathrm{CO}_{2}, \mathrm{~N}_{2} \mathrm{O}$

\section{Introduction}

The environmental degeneration problem caused by human activity and economic development has caused widespread concern, and environmental evolution has been comprehensively studied. From 1970s to 1980 s, the study on the relationship between the environment and development preferred the notion that economic growth caused the environmental degradation according to the

*e-mail: shuowang@jlu.edu.cn materials balance paradigm, thus the famous conclusion was presented that development should be limited [1]. In the macro-level, climate change was studied as the main driving force of environmental change [2]. Different geological sediments in wide temporal scale were studied as evidence of the environmental change process [3]. However, relevant studies are focused on the relationship between development and pollution. Tilman et al. [4] analyzed the influences of agricultural development on environmental change according to the eutrophication caused by extensively applied chemical fertilizers. Tong and Chen [5] made statistical and spatial analyses to 
examine the statistical and spatial relationships of land use and water quality in waters in the State of Ohio. Although the different methods and various theories are more and more accurate and microcosmic for the study of environmental problems recently, the statistical relationship with an inverted-U shape between the income per capita and environmental degradation proposed by Grossman and Krueger [6] has always been discussed, interpreted, and applied in the study of the relationship between the development and pollution under the concept of sustainable development in two decades [7-9]. This statistical relationship was called EKC for its similar shape to the Kuznets curve.

To a certain degree, the discovery of the EKC phenomenon changed the pessimistic prediction about the relationship between development and environment degradation. In a theoretical aspect, the supporters consider the hypothesis as the best and probably the only way to attain a decent environment in most countries [10]. The dissident discussed the reasonability of the methodology and the interpretation of EKC according to the statistics and neoclassical production [11-12]. The explanation of the hypothesis was described in three aspects. Firstly, the scale of production implies that expanding production caused economic development while resource consumption and environmental degeneration was led by the expanding scale of the economy. Secondly, productivity in terms of using less, ceteris paribus of the polluting inputs per unit of output. Thus, technical progress leads to a general increase in gross productivity and lower emission per unit of output [13]. And finally, under rapid development, structural transformation toward information-intensive industries and services, increasing environmental awareness, enforcement of environmental regulations, advanced technology, and higher environmental expenditure relieves environmental degradation [14]. In empirical aspects, the types of main contaminants combined with the GDP or income per capita have been comprehensively studied.

Orubu and Omotor [15] discussed the EKC relationship between the pollutants in air and water (total suspended particulates, TSP, and organisms in water) and income per person in Africa and proposed that the inverted-U cover only existed in air pollution and development. Dogan et al. [16] believed that the EKC relationship exists in $\mathrm{CO}_{2}$ emissions and income in the Organization for Economic Cooperation and Development (OECD) and concluded that the turning point of the inverted-U curve emerged when the secondary industry in total GDP was around $40 \%$. The empirical investigation of EKC about the water contaminant (biological oxygen demanded, BOD) was carried out in 97 countries and showed that the EKC relationship was more significant in North America and Europe than that in Asia, Africa, and Oceania [17]. Chen et al. [18] tested the EKC relationship between solid waste and income for ensuring the effects of different waste management measures. The aggregated material flows were analyzed with the EKC hypothesis in EU and the analysis results showed that the weak EKC relationship existed between economic growth and material flows [19].
In a technological aspect, the new estimation technique was introduced into the empirical research to prove the EKC phenomenon. Martinez-Zarzoso and Maruotti [20] presented the hidden Markov regression models to estimate the relationship between pollution and the development of 28 countries.

According to the aforementioned introduction, undoubtedly the large number of empirical research that used different methods were taken to explain the EKC phenomenon based on the EKC theory [21]. However, two main unsatisfactory phenomena can be grasped in the empirical level. The first is that the different contaminants have different EKC relationships with different shapes (inverted-U, N, etc.) and different inflection points and even some empirical studies have shown that the EKC relationship was not available [22]. Second, there is no feedback to economic production from environmental damage for it is assumed that the income factor is an exogenous variable. The assumption is that environmental damage does not reduce economic activity sufficiently to stop the growth process and that any irreversibility is not so severe that it reduces the level of income in the future [23].

Aiming at the current deficiency in EKC research, this paper presents a new explanation about the EKC hypothesis in the microcosmic view. We analyzed the EKC mechanism based on cost and revenue according to the microeconomics in the different EKC relationships of the different pollutants in different areas. Moreover, we treated economic growth as the endogenous variable that could be affected by environmental degradation. Finally, we undertook the empirical investigation with data of $\mathrm{CO}_{2}, \mathrm{~N}_{2} \mathrm{O}$, and methane emissions in the U.S. to illustrate the explanation.

\section{Material and Methods}

\section{Theoretical Interpretation}

Our research is based on several assumptions. The primary assumption is that economic growth is the social production which can be produced and evaluated with nature resource consumption capacity. The secondary assumption is that economic growth is production rigidity.

In the view of economics, the marginal revenue of a commodity or service is the gain from an increase or loss from a decrease in the consumption of a commodity or service. When economists sometimes speak of a law of diminishing marginal utility, they mean that the first unit of consumption of a commodity or service yields more revenue than the second and subsequent units with a continuous reduction for greater amounts. In EKC phenomenon, the same thing happens. When we are poor, the utility from the development is more obvious than when we are rich. Meanwhile, we prefer development to resource and environment when we are poor. Thus, producers are willing to consume more environmental resources for 
development. That the consumer is willing to pay more in environmental resources for utility from development leads to the producer's private marginal cost being less than the social marginal cost. The externality makes producers high revenue. However, when development is no longer important for the richer consumer, the consumer is not willing to pay more in environmental resources to gain the same utility at the same time. This means that producers' marginal revenue descends and the marginal cost ascends until the marginal revenue equals the marginal cost. We assumed the functions of total revenue, total cost, marginal revenue, and marginal cost to show the explanation directly as follows:

$$
\mathrm{TR}=\mathrm{P} \times \mathrm{Q}
$$

...where TR is total revenue, $\mathrm{P}$ is market price, and $\mathrm{Q}$ is the quantity of the commodity or service.

Marginal revenue is the derivative of total revenue, thus the function of the marginal revenue should be as follows:

$$
\mathrm{MR}=\Delta \mathrm{TR} / \Delta \mathrm{Q}=\mathrm{P}
$$

...where MR is marginal revenue.

In the view of economics and finance, marginal cost is the change in the total cost, which is increased when the quantity is changed in one unit. This is the production cost of one more unit of a commodity. In general terms, marginal cost at each level of production includes all the additional costs required for the production of the next unit [24]. According to the change tendency of total cost, we assumed the function of the total cost as follows:

$$
\mathrm{TC}=\mathrm{A} \times \mathrm{Q} 2+\mathrm{B} \times \mathrm{Q}+\mathrm{C}
$$

...where $\mathrm{TC}$ is the total cost and $\mathrm{A}, \mathrm{B}$, and $\mathrm{C}$ are constants of more than 0 .

$$
\mathrm{MC}=\Delta \mathrm{TC} / \Delta \mathrm{Q}=2 \times \mathrm{A} \times \mathrm{Q}+\mathrm{B}
$$

...where MC is the marginal cost.

According to the marginal decision rule, a commodity or service should be produced at a quantity at which marginal revenue is equal to the marginal cost [25]. Thus the balance quantity of the commodity or service should be calculated as follows:

$$
\begin{gathered}
\mathrm{MR}=\mathrm{MC} \\
\mathrm{P}=2 \times \mathrm{A} \times \mathrm{Q}+\mathrm{B} \\
\mathrm{Q}=(\mathrm{P}-\mathrm{B}) /(2 \times \mathrm{A})
\end{gathered}
$$

Based on the marginal decision rule, we divided the $\mathrm{EKC}$ into four stages as in Fig. 1. In the first stage, marginal revenue is above marginal cost. In this stage, consumers prefer to pay more for utility. Thus, the producer could consume more environmental resources without additional cost. The market price ' $\mathrm{P}$ ' is equal to the marginal cost value in the balance point. ' $\mathrm{P}$ ' is more

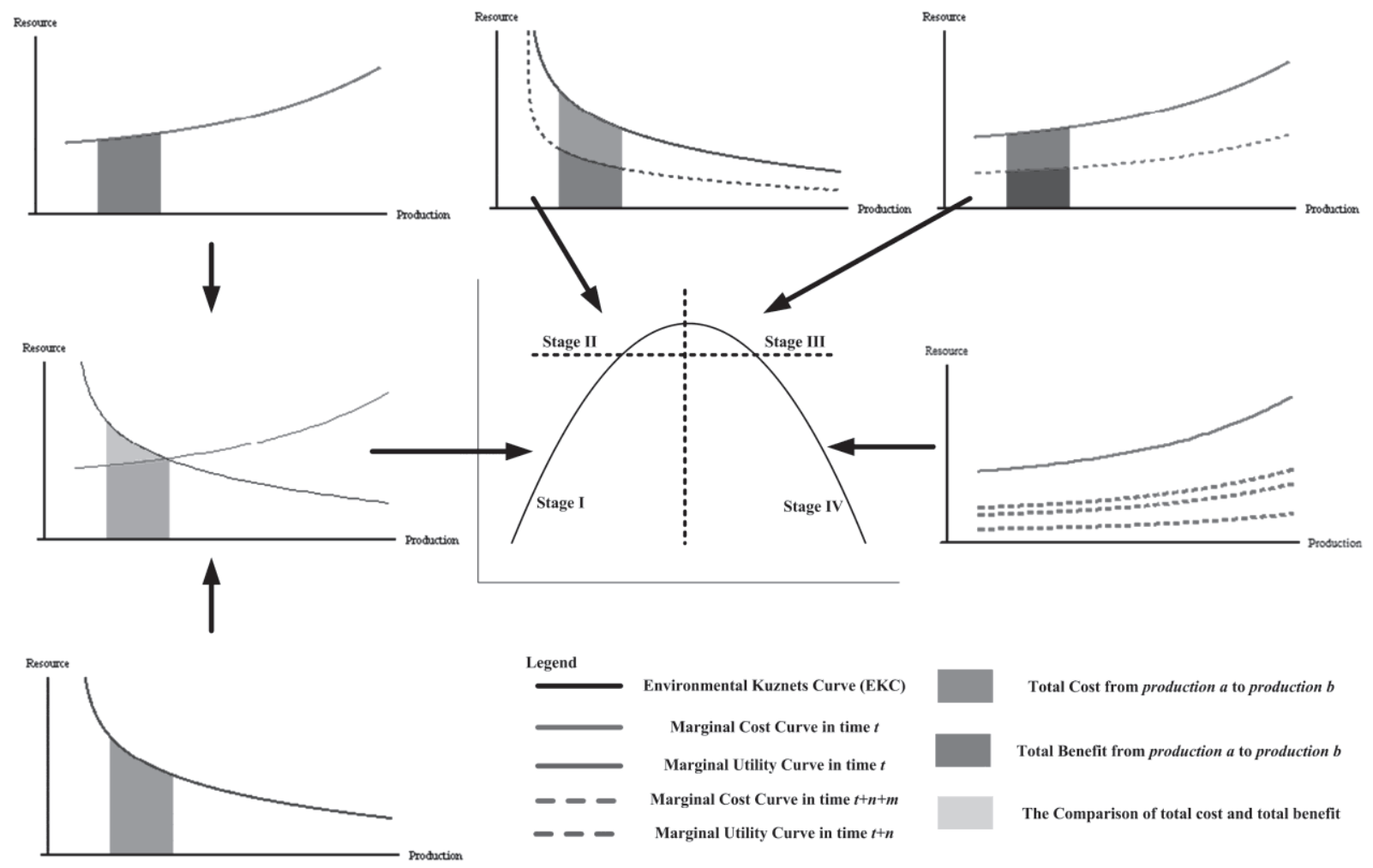

Fig. 1. Theoretical interpretation of EKC hypothesis. 
than 'B,' so we should increase the quantity of investment of the resource and environment for the more income. In the second stage, the fact that the consumer is willing to pay declines, making less marginal revenue. This makes the marginal revenue curve descent and the market price lower, meaning that the value of the new balance point is less than the former. Then the new price ' $\mathrm{P} 1$ ' is less than ' $\mathrm{P}$,' and the new optimal quantity of commodity 'Q1' is less than ' $Q$.' Meanwhile, environmental resource consumption is the investment need to be reduced to produce the new quantity of income in the new balance point. In the third stage, the consumer's willingness to pay continues to descend. Rich consumers are not willing to gain income by pollution and emissions. For producers, it leads to less marginal revenue and more marginal cost. If the marginal cost has no change, the new price descends from 'P1' to 'P2.' Meanwhile, the quantity of production descends from 'Q1' to 'Q2.' According to the aforementioned functions, the optimal quantity of productions is negative when ' $\mathrm{P} 2$ ' ' is less than 'B.' Based on the hypothesis and functions, reducing the value of marginal cost is the reasonable way. 'Q2' is not more than 'Q1' until ' $\mathrm{A}$ ' and 'B' were reduced to 'A1' and 'B1.'

In EKC phenomenon, the economic structural upgrade, science development, and new technology are the main mechanisms for reducing the resource and environment consumption per economic index. In the fourth stage, the process of the third stage continues to occur. Resource and environmental consumption as the investment continues to descend. That makes the inverted U-shape EKC. However, the resource and environment consumptions per economic index will ascend when the marginal cost is less than the market price. That makes the N-shaped
EKC. Based on the explanation above, we inferred that the EKC should be a wave shape abstractly in a long-enough run. Moreover, the developed area has the less marginal revenue of economic growth than the developing area. Thus the EKC hypothesis is proved more easily in the developed than in the developing.

\section{Empirical Method}

Our paper aims to research the relationship between economic growth and environmental degradation. For this purpose, the regression approach has been adopted for analysis. However, the use of time series data for analysis requires testing of stationarity and co-integration of all the variables, and the problem of spurious regression shall be taken into account.

\section{Stationarity Test}

In mathematics, a stationary processed a stochastic process in which joint probability distribution is not changed with time or space. Consequently, existing parameters such as the mean and variance are not changed with time or even their positions.

Let $\left\{X_{t}\right\}$ be a stochastic process, and $F_{X}\left(x_{\mathrm{t} 1+\tau}, \ldots, x_{\mathrm{tk}+\tau}\right)$ represents the cumulative distribution function of the joint distribution of $\left\{X_{t}\right\}$ at times $t 1+\tau, \ldots, t k+\tau$. Then, $\left\{X_{t}\right\}$ is stationary if $F_{X}\left(x_{\mathrm{t} 1+\tau}, \ldots, x_{\mathrm{tk}+\tau}\right)=F_{X}\left(x_{\mathrm{t} 1}, \ldots, x_{\mathrm{tk}}\right)$, for all $k, \tau$, and $t 1+\tau, \ldots, t k+\tau$. Given that $\tau$ does not affect $\mathrm{F}_{\mathrm{X}}($.$) , then$ $F_{X}$ is not a function of time.

In this study, stationarity analysis is used to avoid the pseudo relevance among the variables in the model and as the basis of co-integration.

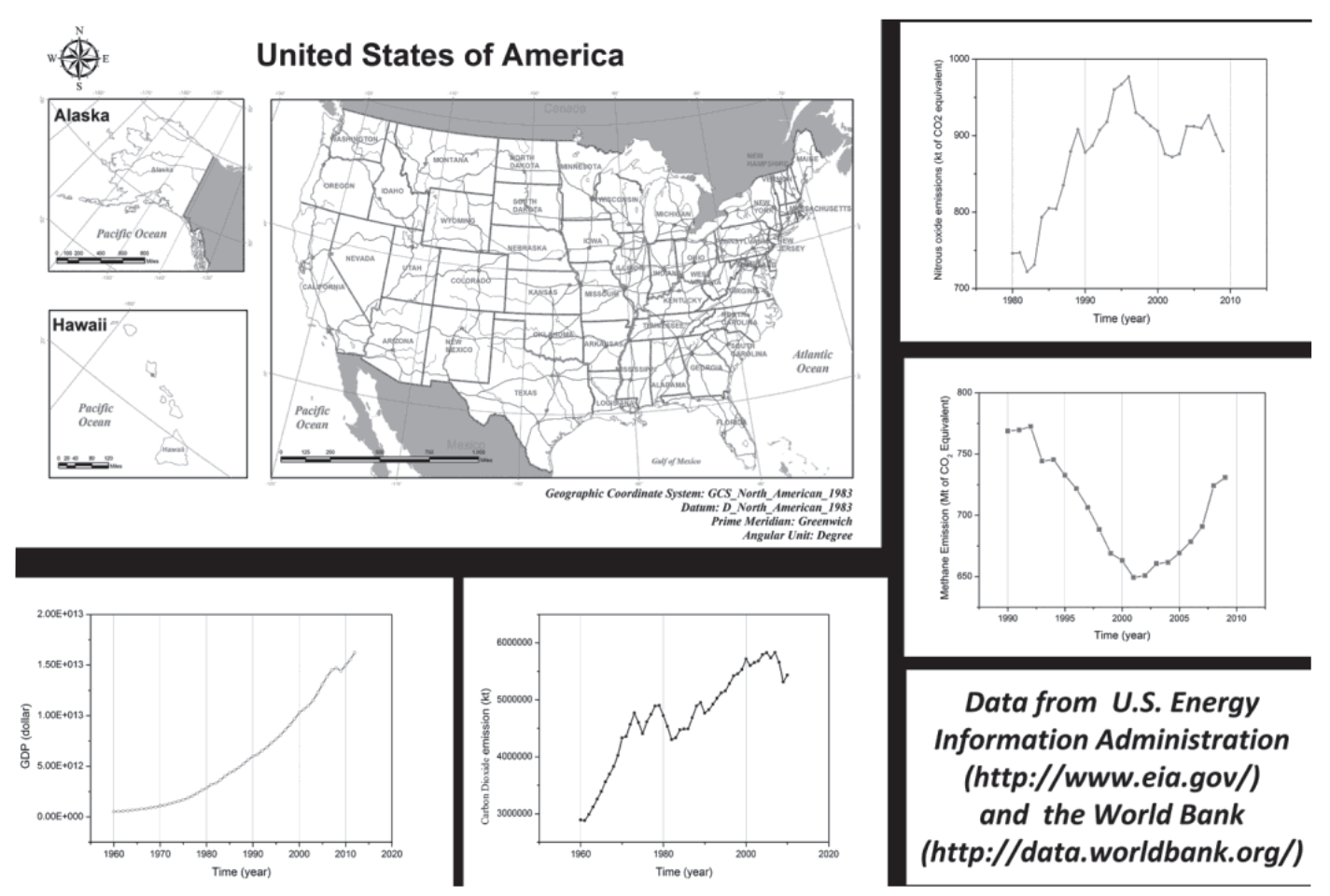

Fig. 2. Research region map. 

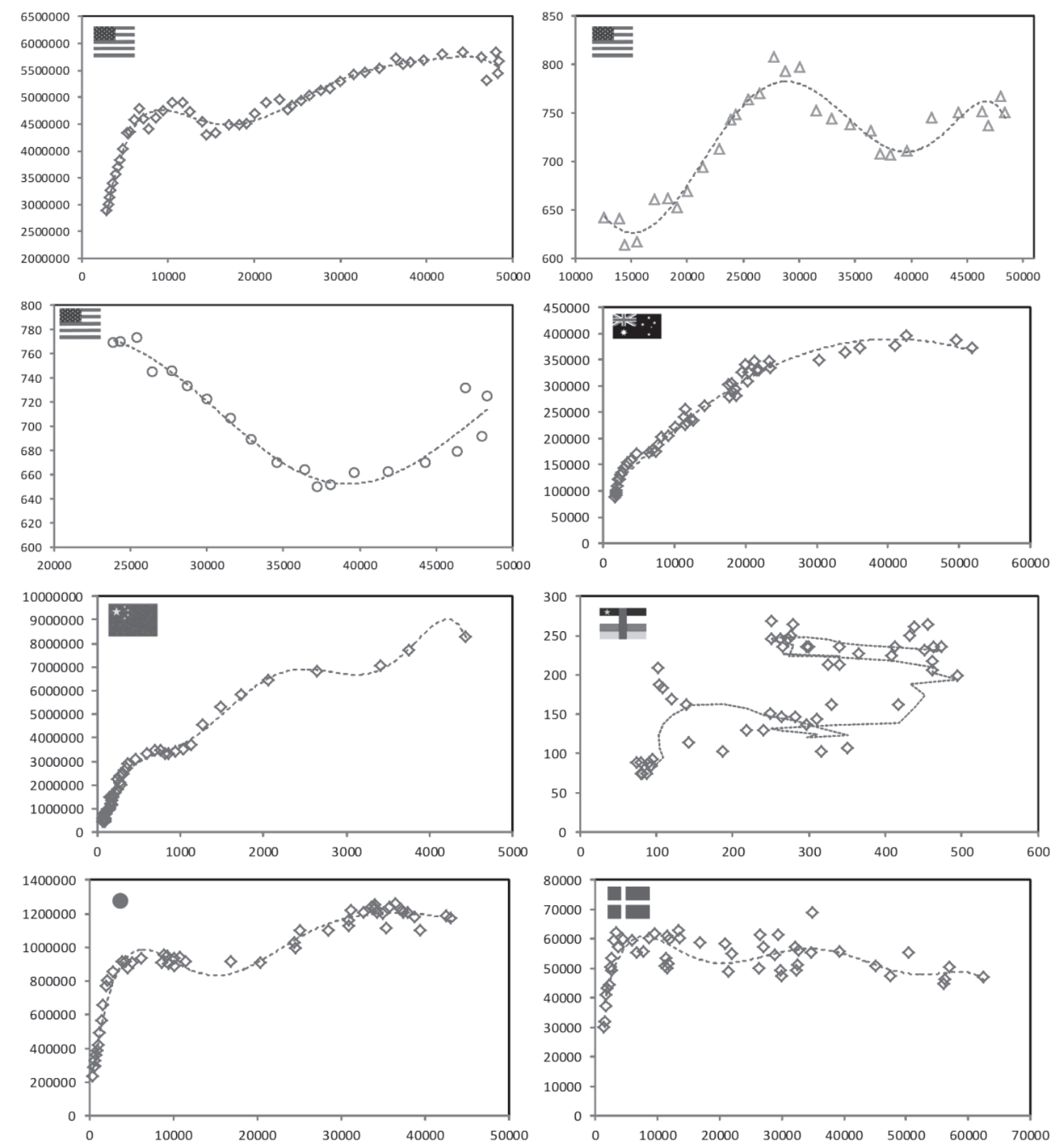

i Legend

i $\mathrm{CO}_{2}$ emissions (Unit:kt) - GDP per Person (Unit: dollars)

! $\triangle \mathrm{N}_{2} \mathrm{O}$ emissions (Unit:kt) - GDP per Person (Unit: dollars) - - Fitness Line

IO Methane emissions (Unit: Million Metric Tons of Carbon Dioxide Equivalent) - GDP per Person (Unit: dollars) !

Fig. 3. EKC phenomenon in the U.S and other countries.

Table 1 . Stationarity test result.

\begin{tabular}{|c|c|c|c|c|}
\hline Index & t-Statistic & $\begin{array}{c}5 \% \\
\text { Level }\end{array}$ & Probability & Order \\
\hline $\begin{array}{c}\text { GDP per } \\
\text { person }\end{array}$ & -4.95 & -3.51 & 0.0012 & 1 \\
\hline $\mathrm{CO}_{2}$ & -4.58 & -2.92 & 0.0005 & 1 \\
\hline $\mathrm{N}_{2} \mathrm{O}$ & -4.24 & -1.95 & 0.0001 & 1 \\
\hline Methane & -2.33 & -1.96 & 0.023 & 1 \\
\hline
\end{tabular}

\section{Co-Integration Test}

If two or more series are individually integrated (in the time series sense) and several linear combinations of them have a lower order of integration, the series are cointegrated. For example, the individual series are the firstorder integrated $[I(1)]$, but several (co-integrating) vectors of coefficients forms a stationary linear combination. Cointegration is the pre-test of the Granger causality. The Granger causality may exist in the co-integration. 
Table 2. Co-integration test result.

\begin{tabular}{|c|c|c|c|c|c|}
\hline Index & Hypothesized & Trace Statistic & $1 \%$ Level & $5 \%$ Level & Probability \\
\hline GDP per Capita & None & 24.31 & 19.94 & 15.49 & 0.0018 \\
\hline $\mathrm{CO}_{2}$ & At most 1 & 8.95 & 6.63 & 6.63 & 0.0028 \\
\hline GDP per Capita & None & 18.77 & - & 15.49 & 0.0154 \\
\hline $\mathrm{N}_{2} \mathrm{O}$ & At most 1 & 6.71 & 6.63 & - & 0.0096 \\
\hline GDP per Capita & None & 19.73 & - & 15.49 & 0.0108 \\
\hline methane & At most 1 & 1.97 & - & 3.84 & 0.1608 \\
\hline
\end{tabular}

\section{Results and Discussion}

\section{General Situation of the Research Zone}

Fig. 2 shows the GDP data of U.S. and economic growth accelerating to $\$ 1.5 \times 10^{13}$ in 2011 . The development speed was especially faster after the 1980s. In contrast with the economic growth of the U.S., the tendency of the main pollutant emissions is more complex, as $\mathrm{CO}_{2}$ emissions increased to $6 \times 10^{6}$ kilotons. From the $1960 \mathrm{~s}$ to the $1970 \mathrm{~s}$, the growth of $\mathrm{CO}_{2}$ emissions was fast. After the middle of the 1970s, emissions descend obviously. From the 1980s to 2009, the emissions ascend in a relatively lower speed. The $\mathrm{N}_{2} \mathrm{O}$ emissions of the U.S. have the different tendency from $\mathrm{CO}_{2}$. From 1960 to 1995 , emissions have continued to ascend. Then the emissions descend obviously from 1996 to 2002. After 2003, there is no obvious tendency in $\mathrm{N}_{2} \mathrm{O}$ emissions. The methane emissions from 1990 to 2009 are a U-shaped curve. From 1990 to 2001, methane emissions descend. The opposite tendency occurs from 2002 to 2009.
EKC Phenomenon in the U.S.

We used the data of GDP per person as the economic index and $\mathrm{CO}_{2}, \mathrm{~N}_{2} \mathrm{O}$, and methane emissions as the environmental index to analyze EKC in the U.S. For the universality of the phenomenon, we used the $\mathrm{CO}_{2}$ emissions data and GDP per person data of Australia, China, Central Africa, Japan, and Demark as the contrastive study. Based on Fig. 3, the relationship between the economic index and the environmental index has no inverted U-shaped curve except for studies in Australia and central Africa. In contrast with the inverted U-shaped curve, the wave shape curve fits the relationship between development and emissions more reasonably. This indirectly proves our hypothesis on the EKC mechanism. According to conditions in the U.S., the wave-shaped curve occurs in $\mathrm{CO}_{2}$ and $\mathrm{N}_{2} \mathrm{O}$ emissions. The methane emissions curve shows the U-shape relationship between development and emissions.

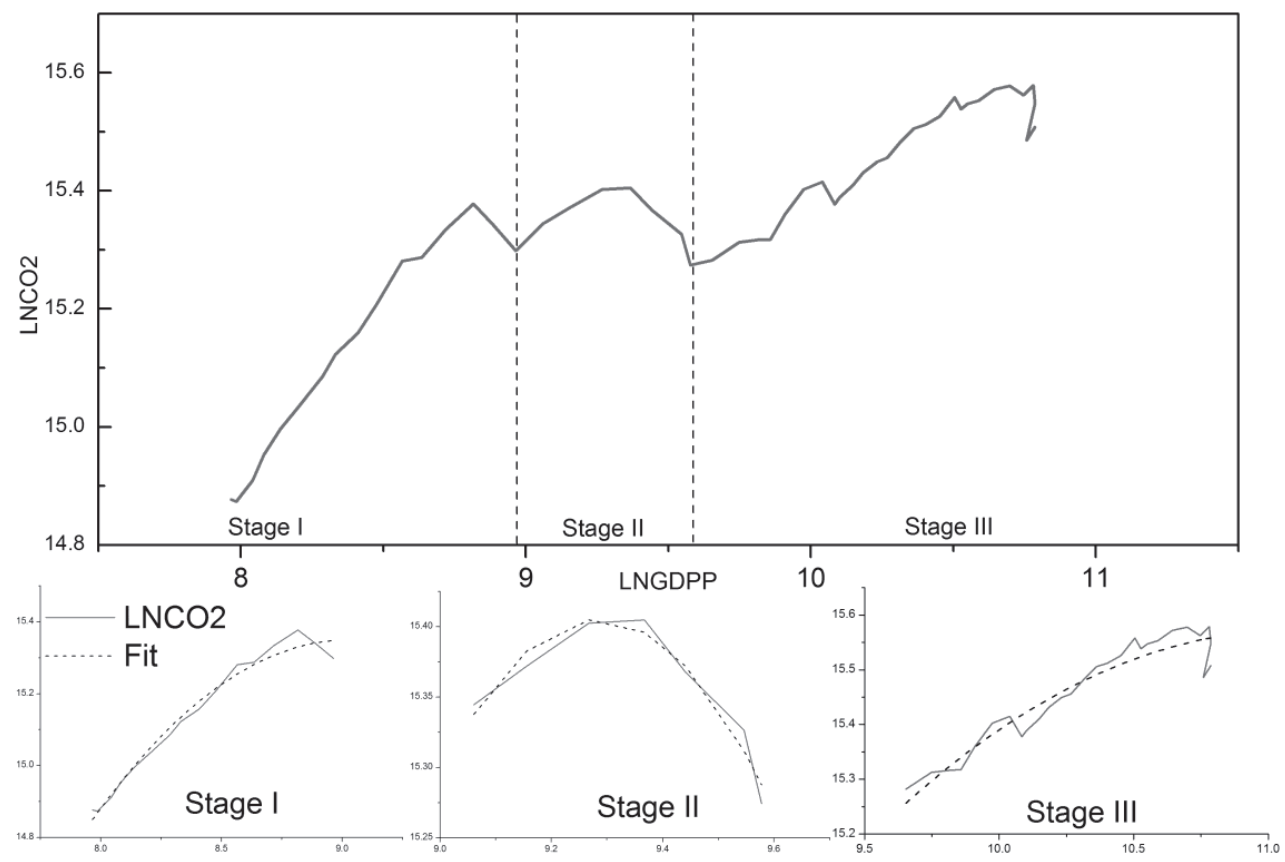

Fig. 4. Curve between GDP per person and $\mathrm{CO}_{2}$ emissions. 


\section{Stationarity and Co-Integration Tests}

Aiming to avoid a spurious correlation, we introduced the stationarity test and co-integration test into our research. We used data of GDP per person and $\mathrm{CO}_{2}$ from 1960 to $2010, \mathrm{~N}_{2} \mathrm{O}$ from 1980 to 2009, and methane from 1990 to 2009. In order to avoid the tendency of time series data, we adopted the logarithm of the data. Thus, the ADF (augmented Dicker-Fuller) test was used to analyze the stationarity with E-views software (Table 1).

According to Table 1, there is no unit root of time series data in the first order. In other words, the time series data of economic growth and pollution in the U.S. is the firstorder stationarity. Thus the co-integration relationship may exist between each other.

Based on the stationarity test, for the time series data has the same order, the co-integration test is available and important to the regression (Table 2).

According to Table 2, there are at most two regression functions between the GDP per capita and $\mathrm{CO}_{2}$, at most two regression functions between the GDP per person and $\mathrm{N}_{2} \mathrm{O}$, and at most one regression function between the GDP per person and methane.

\section{Results}

According to the stationarity test and the co-integration test, there are some relationships between GDP per person and emissions in the U.S. Fig. 4 shows the EKC between the logarithm of GDP per person and $\mathrm{CO}_{2}$ emissions. The curve is not the classic inverted U-shape, but a wave-shaped curve. But in some intervals, the inverted U-shaped curve between the economic index and the environmental index is obvious. In stage I, the U.S. income level is relatively low and the consumer was willing to discharge more $\mathrm{CO}_{2}$ to gain the higher income. That made the producer discharge more $\mathrm{CO}_{2}$ for more revenue. For the producer, discharging more $\mathrm{CO}_{2}$ to produce more fortune until the marginal revenue equals the marginal cost.

In stage II, the inverted U-shaped curve is an almost perfect environmental Kuznets curve. In this stage, the income level is relatively higher and the consumer has no desire for more $\mathrm{CO}_{2}$ emissions for more income. This means that the marginal revenue descended from the original balance point. For gaining more revenue, the producer descends the marginal cost by upgrading economic structure, science, and technology. That makes for more income and less $\mathrm{CO}_{2}$ emissions. But in stage III, the ascendant $\mathrm{CO}_{2}$ emissions occur along the 'unconventional' curve. The marginal cost continues to descend so that the marginal cost is less than the marginal revenue. For optimal revenue, the producer discharges quantities of $\mathrm{CO}_{2}$ for more fortune to satisfy the customer's utility. After stage III, the curve will repeat the process of stage II. Meanwhile, the wave-shaped curve relationship between GDP per person and $\mathrm{CO}_{2}$ emissions proved our hypothesis about the $\mathrm{EKC}$ in a long time series.

Fig. 5 indicates the EKC relationship between $\mathrm{N}_{2} \mathrm{O}$ emissions and GDP per person in the U.S. Based on the

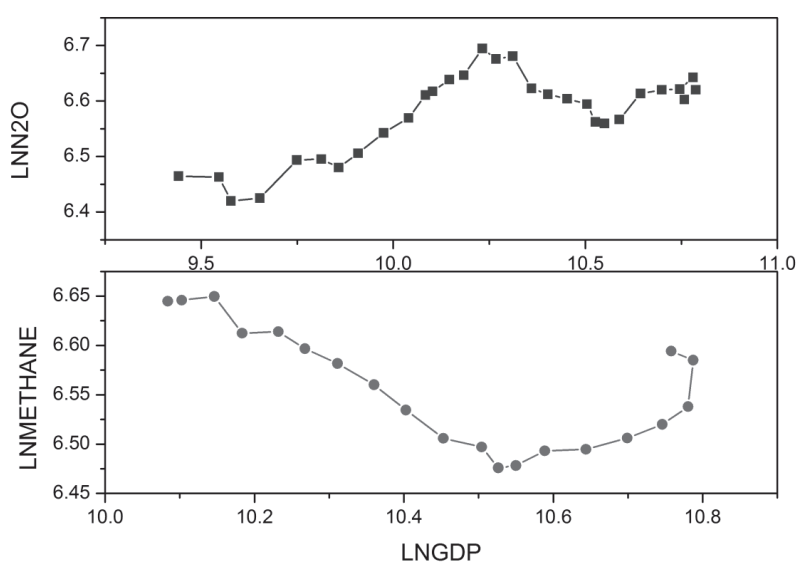

Fig. 5. Curves between GDP per person and $\mathrm{N}_{2} \mathrm{O}$ and methane emissions.

above graph, the $\mathrm{N}_{2} \mathrm{O}$ and GDP per person curve showed the same phenomenon as the $\mathrm{CO}_{2}$ emissions. The graph below shows the U-shaped curve in contrast to the classic inverted-U EKC. The marginal cost continued to descend, in turn pointing to the marginal cost being less than the marginal revenue so that methane emissions were ascendant.

\section{Discussion}

In contrast with the EKCs of Australia, China, Central Africa, Japan, and Demark, the traditional curve is not obvious in our research. The statistics analysis proved that there are correlations between U.S. development and emissions data and the of emissions data. However, the analysis of relationships between the economic index and environmental index of the U.S. indicated that there is no inverted U-shape or N-shape in the long-term series research. The wave-shaped curve between the GDP per person and $\mathrm{CO}_{2}$ emissions proved our guess about the mechanism of EKC indirectly. That the utility of a consumer's income descent leads to a lower market price. Then a producer's marginal revenue descends along with the market price. In our research, this means that to discharge more greenhouse gas (GHG) for more fortune to satisfy the consumer's utility is unable to get more revenue at the constant of marginal cost. For more revenue, the producer has to make less marginal cost than the optimal market price via the more effective economic structure and technology. That makes for a classic inverted-U EKC. Once the marginal cost is much less than marginal revenue, the producer prefers to discharge more greenhouse gas to satisfy a consumer's utility of increasing income. That makes for a wave-shaped curve in a long-term series.

\section{Conclusions}

Our work presents a microeconomic explanation about the EKC hypothesis that differs from the traditional 
macroscopic view, and the empirical investigation of the EKC hypothesis was proposed with the case in the U.S. The wave-shaped curve was proven between the $\mathrm{CO}_{2}$ and GDP per capita based on the stationary, co-integration, and regression tests. The same relationship between $\mathrm{N}_{2} \mathrm{O}$ and the economy existed in the U.S., and we presented the microeconomic interpretation about the new wave shape relationship in empirical research. According the current research, the conclusion that growth is the only and best way to deal with environmental degradation is overoptimistic in some sense. The fact that education and promotion reduces the willingness to pay more resources for more income is more significant for reducing the marginal revenue of producing fortune. The fact that economic structural upgrade and technological development reduces resource consumption is also significant for reducing the marginal cost of economic development.

Thus our future work will be focused on two aspects: to confirm the quantitative marginal utility and marginal cost in the empirical research and prove our explanation directly; and to confirm the quantitative impact of the natural and social index.

\section{Acknowledgements}

The authors gratefully acknowledge the financial support for this study provided by the Major Science and Technology Program for Water Pollution Control and Treatment in China (2012ZX07202009).

\section{References}

1. KOEHLER J.E. The Limits to Growth: A Report for the Club of Rome's Project on the Predicament of Mankind. By Donella H. Meadows, Dennis L. Meadows, Jørgen Randers, William W. Behrens III. (New York: Universe Books, Pp. 205. \$2.75.). 1974: New ... Library. 513, 1972.

2. ARNELL N.W. Climate change and global water resources: SRES emissions and socio-economic scenarios. Global Environmental Change, 14 (1), 31, 2004.

3. OVERPECK J., ZIELINSKI G. Arctic Environmental Change of the Last Four Centuries. Science, 278 (5341), 1251, 1997

4. TILMAN D., FARGIONE J., WOLFF B., D‘ANTONIO C., DOBSON A., HOWARTH R., SCHINDLER D., SCHLESINGER W.H., SIMBERLOFF D., SWACKHAMER D. Forecasting agriculturally driven global environmental change. Science, 292 (5515), 281, 2001.

5. TONG S.T., CHEN W., Modeling the relationship between land use and surface water quality. Journal of Environmental Management, 66 (4), 377, 2002.

6. GROSSMAN G.M., KRUEGER A.B. Environmental Impacts of a North American Free Trade Agreement. Social Science Electronic Publishing, 8 (2), 223, 1992.

7. PAUDEL K.P., SCHAFER M.J. The Environmental Kuznets Curve Under a New Framework: The Role of Social Capital in Water Pollution. Environmental and Resource Economics, 42 (2), 265, 2009.
8. NASIR M., REHMAN F.U. Environmental Kuznets Curve for carbon emissions in Pakistan: An empirical investigation. Energy Policy, 39 (3), 1857, 2011.

9. XIA J., JIA S., YANG H., WANG L., ZHANG S. Industrial Water Use Kuznets Curve: Evidence from Industrialized Countries and Implications for Developing Countries. Journal of Water Resources Planning \& Management, 132 (3), 183, 2006.

10. BECKERMAN W. Economic growth and the environment: whose growth? whose environment? World Development, 20 (4), 481, 1992.

11. PERMAN R., STERN D.I. Evidence from panel unit root and co-integration tests that the Environmental Kuznets Curve does not exist. Australian Journal of Agricultural and Resource Economics, 32 (3), 325, 2003.

12. STERN D.I. The Rise and Fall of the Environmental Kuznets Curve. World Development, 32 (8), 1419, 2004.

13. STERN D.I., COMMON M.S., BARBIER E.B. Economic growth and environmental degradation: The environmental Kuznets curve and sustainable development. World Development, 24 (7), 1151, 1996.

14. PANAYOTOU T. Empirical Tests and Policy Analysis of Environmental Degradation at Different Stages of Economic Development. Ilo Working Papers, 4, 1993.

15. ORUBU C.O., OMOTOR D.G. Environmental quality and economic growth: Searching for environmental Kuznets curves for air and water pollutants in Africa. Energy Policy, 39 (7), 4178, 2011.

16. DOGAN E., SEKER F. An investigation on the determinants of carbon emissions for OECD countries: empirical evidence from panel models robust to heterogeneity and crosssectional dependence. Environmental Science and Pollution Research, 23 (14), 14646, 2016.

17. CHIENCHIANG L., YIBIN C., SUN C.H. The environmental Kuznets curve hypothesis for water pollution: do regions matter? Energy Policy, 38 (1), 12, 2010.

18. CHEN C.C., CHEN Y.T. Income effect or policy result: a test of the environmental Kuznets Curve. Journal of Cleaner Production, 16 (1), 59, 2008.

19. VEHMAS J., LUUKKANEN J., KAIVO-OJA J. Linking analyses and environmental Kuznets curves for aggregated material flows in the EU. Journal of Cleaner Production, 15 (5), 1662, 2007.

20. MARTINEZ-ZARZOSO I., MARUOTTI A. The environmental Kuznets curve: functional form, time-varying heterogeneity and outliers in a panel setting. Environmetrics, 24 (7), 461, 2013.

21. KAIKA D., ZERVAS E. The Environmental Kuznets Curve (EKC) theory - Part A: Concept, causes and the $\mathrm{CO}_{2}$ emissions case. Energy Policy, 62 (5), 1392, 2013.

22. KAIKA D., ZERVAS E. The environmental Kuznets curve (EKC) theory. Part B: Critical issues. Energy Policy, 62 (9), 1403, 2013.

23. ARROW K., BOLIN B., COSTANZA R., DASGUPTA P., FOLKE C., HOLLING C.S., JANSSON B.O., LEVIN S., MÄLER K. Economic growth, carrying capacity, and the environment*. Ecological Applications, 268 (1), 89, 1996.

24. HENDERSON J.V., POOLE W. Principles of microeconomics. South-Western Pub. Co. 200-201, 1986.

25. CONSTITUTION T.U.S. Economics: Principles in Action. Pearson Prentice Hall, 2007. 